\title{
CTATTI
}

\section{РАННЬОМОДЕРНА ФИОСОФІЯ}

\author{
Сергей Секундант
}

\section{ХРИСТИАН ТОМАЗИЙ: ЛОГИКА КАК УЧЕНИЕ О РАЗУМЕ}

В конце XVII - начале XVIII века Христиан Томазий (Christian Thomasius, 1655$1728)$ был, пожалуй, самым популярным философом в Германии. Ему единственному из эклектиков удалось создать школу, и это при том, что эклектизм резко выступал против всякого рода сект. Сын Якоба Томазия, учителя Лейбница, X. Томазий своей популярностью и влиянием превзошел своего отца. Именно он, а не Иоганн Христофор Штурм, сделал эклектизм наиболее модным течением в немецкой философии этого периода и именно его следует считать основоположником немецкого Просвещения. Для нас он интересен в нескольких отношениях: во-первых, как своеобразный представитель немецкого эмпиризма, во-вторых, как реформатор философии и, в-третьих, как реформатор логики. Предметом данной статьи будет его реформа логики, потому что именно в этой области он более всего недооценен исследователями его творчества.

Уже Петер Петерсен довольно критически, если не пренебрежительно, отзывается о его «Введении в учение о разуме» (Einleitung zu der Vernunfft-Lehre): «Мы не имеем перед собой действительно глубокого логического труда. Там, где он воюет против аристотелевской логики, он некритически погружается в доморощенные рассуждения и при этом нигде не сбрасывает одеяние старой логики» [Petersen 1921: 387]. Такого рода оценки вполне объяснимы, поскольку Томазий ${ }^{1}$ довольно критически относился к формальной логике, которая стала доминирующей в начале XX в. Именно этим обстоятельством обусловлена критика логического учения Томазия. Последнее большинство исследователей считали психологическим и, следовательно, тупиковой ветвью в развитии логики. Однако ситуация существенным образом изменилась в середине 50-х годов XX в., когда логики осознали ограниченность формальной логики и стали разрабатывать разного рода теории аргументации («неформальная логика», «новая риторика», «коммуникативная логика» и т.д.), ориентированные на содержательный контекст дискурса. В этой связи вопрос о том, какое из направлений является тупиковым, можно считать проблематичным. Однако логика

(C) С. Секундант, 2017

${ }^{1}$ В дальнейшем изложении под Томазием следует понимать именно Христиана Томазия. 
Томазия нас интересует прежде всего в историко-философском контексте. Появившись на двадцать лет раньше, чем логика Х. Вольфа, она стала частью его реформы философии и оказала серьезное влияние на дальнейшее развитие не только логики, но и философии в Германии вплоть до Канта.

\section{«Придворная философия». Программа реформы икольной философии}

Основная идея реформы философии, которую предпринял Томазий, сводилась к тому, чтобы сделать ее максимально полезной для человека, особенно в общественной жизни. Новую философию он противопоставляет философии «школы», - господствовавшей в немецких университетах того времени и по своей природе сектантской - и называет ее «придворной философией» (Philosophia aulica) или «философией двора» (Hof-Philosophie). Новая философия должна была бы ориентироваться преимущественно на светскую молодежь. Она предстает уже как светская мудрость (Welt-Weisheit), a ее методологической основой становится эклектизм [Thomasius 1710: 53 (I, §96)]. Вернер Шнайдер считает, что на Томазия в этом отношении оказали влияние аббат Арман де Жерар (Abbé Armand de Gérard), автор «Философии придворных» («La Philosophie des Gens de Cour»), выдержавшей с 1680 г. три издания, а также Франсуа де Ля Мот Ле Beйе (François de La Mothe Le Vayer). Однако сам Шнайдер признает, что Арман де Жерар больше занимается физикой и фактически игнорирует логику. Единственное, что их объединяет, это обращенность их трудов преимущественно к les honnétes gens (благородным людям) и le beau monde (представителям высшего света) [Schneiders 1993: ХII].

Противопоставляя эклектическую философию сектантской, Томазий под «сектой» в широком смысле понимает философию, «которая следовала или методу преподавания некоторого определенного предшественника, или его способу философствования», а в «точном смысле» сектантами он называет философов, «которые остаются связанными с постулатами определенного учителя и защищают их, руководствуясь более или менее сильным [weiblichen] аффектом и слепым пристрастием [Zuplatzen]» [Thomasius 1710: 49-50 (I, §89)]. Оппозиционность эклектизма в том его понимании, котрого придерживался Томазий, именно сектантской (догматической) философии находит свое отражение уже в определении эклектической философии. «Эклектической» Томазий называет такую философию, «которая требует не зависеть только от высказываний одного философа и не связывать себя обязательствами считать окончательными слова одного единственного наставника, а на основе высказываний и писаний всех учителей собирать в сокровищницу своего рассудка все то, что есть у них истинного и хорошего. Она также не опирается на авторитет учителя, а на основе самостоятельного исследования принимает решение, является ли то или иное положение обоснованным, а также добавляет нечто от себя. Таким образом, она смотрит своим собственными глазами, а не глазами другого» [Thomasius 1710: 50 (I, §90)].

Основные его требования к философу-эклектику сводятся к следующим: 1) не зависеть только от высказываний одного философа; 2) не считать слова одного единственного наставника окончательными; 3) принимать во внимания слова и писания всех учителей; 4) отбирать все то, что есть у них истинного и хорошего; 5) не ссылаться на авторитет учителя, а принимать решение на основе самостоятельного исследования; 6) только после тщательного исследования добавлять нечто от себя; 7) смотреть на вещи своими глазами, а не глазами другого, т.е. не пересказывать мысли других, а мыслить самостоятельно. 
В отличии от сектантов, синкретистов и тех эклектиков, которые подменяли философию историей философии, философ-эклектик для Томазия - это самостоятельный мыслитель (Selbtdenker), который ищет истину и критически оценивает учения предшественников. Уточняя методологическую позицию эклектической философии, Томазий пытается оградить ее от других философских течений и, прежде всего, от синкретизма. К виднейшим представителям синкретизма он относит Антиоха из Аскалона и Цицерона, которые смешивали философию Платона и Аристотеля, а также Пико делла Мирандолу и представителей Итальянской академии. Такого рода синкретизм, согласно Томазию, «противоречит здравому смыслу и из философа делает софиста» [ibid., 48 (I, §87)]. Синкретисты, пишет он, «благодаря своим неумелым сравнениям превращают определенные учения в неопределенные» [ibid., 50 (I, $\S 89)]$. Дистанцируется Томазий и от пирронистов, т.е. скептиков, «которые совершенно ни во что не верят», а также от мистиков и схоластов.

Томазий привносит в философию дух критицизма, который принципиально отличается от декартовского. Как известно, обращение к мнениям предшественников Декарт считал не только бесполезным, но и вредным. Путь мнений, на его взгляд, ведет в никуда. В этом он видел главный недостаток всей предшествующей философии. Только опираясь на естественный свет разума и отбрасывая все сомнительное, можно, согласно Декарту, прийти к достоверному знанию истины. Однако уже И. Х. Штурм показал, что в процессе дедукции из принципа cogito философских следствий Декарт активно использовал знания, полученные предшественниками, причем часто некритически. Поэтому, считает Томазий, всякое философствование должно начинаться с критического анализа мнений предшественников. Для Томазия познание - это диалогический процесс. Любая точка зрения должна получить свое обоснование в полемике с другими точками зрения. Поэтому, считает он, всякое изложение философии должно начинаться с историко-философского введения, критического по своему характеру.

На важную критическую функцию истории философии в программе эклектической философии Томазия указывает Вильгельм Шмидт-Биггеман. «Эффект исторической предпосылки, - пишет он, - состоит в том, что последняя с помощью истории философии парализует метафизику. Благодаря познанию многообразия сект и противоречивости представленных в истории мыслей, ее претензии на абсолютную истину становятся неубедительными» [Schmidt-Biggemann 1988: 38]. С другой стороны, экскурс в историю философии, по его мнению, должен был обосновать легитимность эклектической программы, «концепцию действующей не сектантски, а миролюбиво настроенной (irenisch gesinnten) и ориентированной на практику философии» [ibid., 319]. Обращение к истории философии важно было и для логики. «Чтобы придворный философ мог отличить истинное умозаключение от ложного, - поясняет Леманн-Браунс, - он должен был прежде обратиться к истории философии, которая имеет дело с задуманной им [Томазием - C.C.] реформой логики, и понять никчемность раздутой силлогистики» [Lehmann-Brauns 2004: 318]. Знание истории философии позволяет нам избавиться от предрассудков как в философии, так и в логике. В этом, пожалуй, заключается основная функция историко-философского введения.

Вслед за Декартом в качестве инструмента критики Томазий избирает сомнение. Однако он отмежевывается как от радикального сомнения скептиков, так и от методического сомнения Декарта. Томазий различает скептическое сомнение (dubium scepticum), которое сомневается в истине вообще, от догматического сомнения (dubium dogmaticum), которое предполагает существование истины [Thomasius 1773: 
858]. Он считает, что сомневаться во всем невозможно. Даже радикальное сомнение предполагает нечто, что не ставится им под сомнение. Этим нечто, как правило, выступает здравый рассудок. «Хотя любитель мудрости (Weisheit-Liebender), - пишет Томазий, - не является сектантом, он все же не является ни врагом философии, ни синкретистом. Он - эклектик, который из всех философских сект извлекает истины, отмечает их ошибки и все учения оценивает с точки зрения здравого смысла (an dem Probierstein der gesunden Vernunft streichet) [Thomasius 1713: 135 (VI, §95)].

Скепсис Томазия направлен преимущественно на критику предрассудков. «Предрассудок авторитета», неразумную любовь к другому человеку, и «предрассудок поспешности» (Übereilung), поспешность в собственном суждении, Томазий считает главными предрассудками разума, а «подражание» (Nachahmung) и «нетерпимость» (Ungeduld) - предрассудками воли. Эти предрассудки, а также «чрезмерное доверие» (übermäßiges Vertrauen), «недоверие» (Mißtrauen) и т.д. суть качества, которые, по его мнению, препятствуют познанию истины. «Догматический скептицизм» - это альтернатива традиционным формам догматизма и скептицизма. Он ориентирован на развитие таких свойств личности, которые способствовали бы получению нового знания. Скепсис у Томазия, как и у Декарта, направлен на то, чтобы освободить сознание человека от гнета традиции. Но на этом их сходство заканчивается. Основную свою задачу Томазий видит в том, чтобы сформировать творческую личность, и один только скепсис здесь не поможет. Творческая личность должна обладать не только определенными нравственными качествами (скромность, осторожность, толерантность, самостоятельность, беспристрастность и т.д.), но также критическим мышлением и способностью к плодотворному труду. Цель же Декарта - указать метод, который может гарантировать достоверное познание истины. Декарт пытается доказать возможность построения системы метафизики на достоверных началах, а Томазий критически относится к метафизике вообще и априорным системам в особенности.

Скепсис и критика выполняют у Томазия различные функции. На это указывает Леандер Шольц. «Скепсис для него, - пишет он о Томазии, - это способность прерывания традиционных информационных авторитетов. Критика - это способность дифференцирования и отбора различных источников информации. Наконец, разумное суждение (kluge Urteil) - это способность установить связь между собой и знанием, которое в конечном счете должно найти свое практическое применение» [Scholz 202: 55]. Хотя Томазий отождествляет здравый рассудок с естественным светом ума, его критицизм отличается от декартовского в двух отношениях. Во-первых, он не ограничивается апелляцией к обыденному разуму или к своей интуиции, а использует естественный свет разума в процессе анализа различных точек зрения и их оснований. У Томазия это фактически уже исторический разум, который претендует не только на преодоление ограниченности прежних точек зрения, но и на сохранение всего того, что в них было ценного с точки зрения познания истины. Во-вторых, как философским, так и историко-философским и логическим изысканием он предпосылает исследование разума, которое, собственно, и становится у него основанием критики. Наконец, Томазий ограничивает сферу действия естественного света разума тем, что может быть подтверждено опытом, четко разграничивая свет человеческого разума и свет откровения, теологию и философию.

Томазий определяет философию как «такую интеллектуальную и инструментальную способность (habitus intellectualis et instrumentalis), которая рассматривает Бога, а также естественную и нравственную деятельность человека в соответствии со светом 
разума и исследует ее причины для пользы человеческого рода» [Tomasius 1710: 71 (II, §31)]. Мы видим, что Томазий, с одной стороны, выводит теологию за рамки философии, а с другой - ориентирует ее на практическую цель [Tomasius 1688: 68 (c. II, §65)]. Она должна приносить пользу человечеству и не ограничиваться чистым созерцанием (blosse Betrachtung) [ibid., 82 (II, §65)]. Хотя «придворная философия» ориентирована на практику и пользу, именно она, согласно Томазию, должна занять место первой философии (philosophia prima) [ibid., 203 (XI, §25)]. Метафизика, по его мнению, является царицей наук, но только тех, которые имеют дело с ложными и обманчивыми [erronea] вещами, занимаются выдумками лукавых и праздных людей [commenta astutorum \& otiosorum hominorum], а не направлены на надежное познание вещей [ibid., 203 (XI, §32)]. В соответствии с этим определением Томазий делит придворную философию на две части - инструментальную (instrumentalis) и основную (principialis). Инструментальная философия занимается словами или вещами, которые выражены словами. К ней он относит грамматику, языкознание, риторику, поэзию и красноречие, а также нынешнюю метафизику, понимаемую как простой набор слов. К инструментальной философии Томазий относит и логику. В отличие от риторики, которая изучает преимущественно красоту слов, задача логики - оценивать аргументы [ibid., 68-69 (II, §67)]. Основную философию Томазий в свою очередь делит на теоретическую и практическую. Теоретическая философия рассматривает или творца (поскольку он может быть познан на основе естественного света разума, чем когда-то занималась пневматика, первая часть метафизики), или творениями. Сущность творений изучает физика, а их количественную сторону - математика. Практическая часть рассматривает человеческие действия с точки зрения требований добродетели и пользы. К ней относится этика, политика и экономика [ibid., 69 (II, §68)].

\section{«Учение о разуме». Программа реформы логики}

Изложенная Томазием в «Introductio ad philosophiam aulicam» («Введение в придворную философию») (1688) программа реформы философии имела ярко выраженную прагматическую направленность. Новая философия должна была стать практическим руководством прежде всего для юридически образованной придворной молодежи и была направлена против далекой от практических потребностей школьной философии, в частности против схоластической метафизики и логики. Именно этот контекст во многом определил характер логики Томазия, а также использование им при ее изложении немецкого языка. На это указывает Вольфганг Менцель, который, сравнивая логику Томазия и его ученика Гундлинга с логикой Христиана Вольфа, пишет: «Томазий и Гундлинг понимали свою логику прежде всего, как пропедевтику общественной деятельности. Томазия не интересовали теоретические условия возможности познания, у него речь шла о содержании мышления, прежде всего с точки зрения нравственной перспективы, а также о практических условиях познания. Здесь его логика психологически ориентирована. Поэтому именно она считается первой логикой, использующей немецкий язык» [Menzel 1996: 215]

В предисловии к своему «Введению в учение о разуме», которое было написано в 1690 г., но появилось в печати в 1691 г., Томазий свою цель видит в том, чтобы «отыскать главные источники всех предрассудков и из них вывести разные вытекающие из них следствия, которые препятствуют нам в познании истины в различных дисциплинах и науках» [Thomasius 1699: 26]. Конечная же его цель практическая: «увеличить у учащейся молодежи желание освободится от уничижающего ярма недостоверности» 
[ibid., 27]. Он не скрывает, что в этом следует Декарту. По его мнению, Декарт «был первым, кто в последнее время обратил внимание на предрассудки, которые мешают нам в познании истины, и более подробно, чем другие, исследовал их виды и природу» [ibid., 25]. Но Декарт, по его мнению, сам был не свободен от предрассудков. В ориентации Томазия на практический дискурс, на естественную логику разума не трудно увидеть влияние Пьера де ла Раме, которого он считал самым выдающимся философом. К своим предшественникам Томазий также относил Лоренцо Валлу и Луиса Вивеса [Thomasius 1710: 41 (I, §74)].

В своей логике Томазий делает упор не столько на форму, сколько на содержание наших рассуждений. Предметом логики у него становится способность рассудка «отличить истинное от ложного, доброе от злого и указать их обоснованно истинные или по возможности вероятные причины» [Thomasius 1699: 1-2 (I, §1)]. Эту способность он называет ученостью (Gelahrheit), которая «имеет свое местопребывание в рассудке человека и потому она обща всем людям» [ibid., 2 (I, §2)]. Согласно Томазию, все люди способны достичь учености, хотя некоторые по разным причинам ею не обладают. Ее он отождествляет с естественным светом или самим рассудком (Verstand), «благодаря которому человек способен, опираясь на естественные силы, получить истинное и отчетливое понятие о чувственных и земных вещах, полезных для этой временной жизни» [ibid., 5 (I, §16)]. Этот естественный свет Томазий иногда называет «внутренним разумом» (Vernunft), противопоставляя его сверхъестественному свету божественного Откровения. Сверхъестественный свет, который является источником нашего знания о Боге (Gottes-Gelahrheit), Томазий ставит выше естественного света, являющегося источником мирской мудрости (Welt-Weißheit), но подчеркивает, что 1) один свет не противоречит другому и что 2) без «человеческого откровения» невозможно постичь божественное [ibid., 7 (I, §23)].

Мирская мудрость, согласно Томазию, «нуждается в учении о разуме как основании всей ее науки» [ibid., 8 (I, §27)]. Основная цель учения о разуме состоит в том, чтобы «очистить свой рассудок от всех предрассудков, познать ложные умозаключения и защитить себя от софистических интерпретаций» [ibid., 9 (I, §30)]. Учение о разуме Томазия - это попытка построения «естественной» логики, которую он противопоставляет искусственной логике схоластиков, и как таковое оно у него получает антропологическое обоснование. «Это учение, - пишет Томазий, - основывается на разуме самого человека и, таким образом, от природы дано человеческому роду самим Богом [ibid., 13 (II, §3)]. Оно не учит ничему сверхъестественному, а только «указывает, как нужно от природы пользоваться разумом, или, скорее, как нужно избавляться от затемнений естественного света» [ibid., 13 (II, §3)]. Вслед за скептиками и Декартом Томазий становится на точку зрения гносеологического субъекта. Учение о разуме у него служит основанием мирской мудрости, но только в качестве «общего инструмента учености» [ibid., 14 (II, §8)]. Оно «должно давать главные правила познания истины, которые могут использоваться повсюду» [ibid., 15 (II, §3)]. Конечной целью учения о разуме у него является истина. Однако эта цель включает в себя достаточно широкий круг задач, в том числе и определение границ разума. В отличие от Декарта, который верил в неограниченные возможности разума отличить истину от лжи, Томазий, подобно скептикам и эмпирикам, считает, что человеческий разум в силу своей слабости часто вынужден довольствоваться вероятностью. «Поскольку слабость человеческого разума такова, - пишет он, - что невозможно точно и отчетливо познать все истины или гарантировать достоверность тех истин, которые человек знает, постольку доста- 
точно, если учение о разуме только покажет, как следует отличать бесспорно истинные высказывания от бесспорно ложных, а также в других вещах познать, можно ли и в какой мере постичь их вероятность, и как далеко может продвинуться человеческий разум со своей ученостью (Wissenschaft)» [ibid., 16 (II, §15)]. Поскольку учение о разуме должно не только научить человека тому, как достичь истин, но также показать, как он должен служить человеческому роду, то оно «не только инструмент учености, но первая и необходимая часть ее» [ibid., 16 (II, §16)]. Исходя из этого Томазий выделяет в учении о разуме две части: «В первой говорится вообще о человеческом разуме, об истине, о первых признаках и основных правилах, о различных вещах, на которые разум распространяет истину, о средствах изучения неизвестных истин, о методе и порядке, которые использовались до сих пор и т.д.» [ibid., 16-17]. Другая часть «рассматривает, в частности, как следует вести себя, если хотят 1) для себя исследовать истину, 2) сообщить познанные истины другому, 3) понять мнения других людей, 4) судить о них и 5) опровергать их» [ibid., 17 (II, §18)].

Подобно Декарту, Томазий подчеркивает, что ученость не зависит от формальной правильности и, следовательно, от силлогистики. Уже в подзаголовке своего «Введения в учение о разуме» в качестве цели своего труда он указывает «легким и доступным всякому человеку... способом, не прибегая к силлогистике, показать путь взаимного отличения истинного, вероятного и ложного, и открыть новые истины». В отличие от Декарта, который делал акцент на интуитивной очевидности суждений гносеологического субъекта, Томазий считает, что ученость является преимущественно продуктом рационального дискурса. Поиск истины осуществлялся не на основе формально правильных фигур силлогизма, а в ходе содержательного дискурса (Discursus), который не имеет формы силлогизма [Thomasius 1688: 198 (IX, §4)]. Разумность аргумента, по его мнению, обнаруживается только в рациональном дискурсе. Томазий резко выступает против того, чтобы сводить логику к силлогистике. Последняя, считает он, может служить каноном при оценке практической разумности мыслей, но не органоном для открытия новых истин. Хотя схоластики разграничивают метод, или способ обучения (Lehr-Art), который состоит в доказательстве истинности каких-либо положений, и порядок (Ordnung), который заключается в правильной связи доказательств, они с помощью силлогистики фактически занимались только упорядочиванием уже полученных знаний. Согласно Томазию, это вытекает из природы самого силлогизма. Мы не можем создать силлогизм, замечает он, если не имеем трех терминов. Чтобы отыскать средний термин, благодаря которому только и становится возможным переход от посылок к заключению, т.е. новому суждению, мы должны уже знать заключение. Таким образом, чтобы составить силлогизм, мы должны иметь уже истину. Это дает основание Томазию утверждать, что силлогизм является не средством для открытия истины, а только способом упорядочения или украшения уже открытой истины.

Томазий также указывает на то, что ни один из методов, о которых говорила схоластика, не использовал силлогизм. Поскольку метод (Methodus, Lehr-Art) должен привести к неизвестным истинам, то первое и единственное правило метода, согласно Томазию, состоит в том, что «всегда нужно идти от более известных вещей к менее известным (a notioribus semper debere progredi ad minus nota) [ibid., 177 (X, §2)]. Факт безконечного изменения человеческих знаний, в силу которого то, что одним известно хорошо, от других может быть скрыто, свидетельствует, согласно Томазию, о невозможности дать какие-либо особые правила метода (regula speciales de methode tradi nequeunt). Каждый должен полагаться на свой ум, который только и решает, как пра- 
вильно применять аргументы, а это значит, что метод всегда должен быть произвольным (methodum semper esse arbitrariuam) [ibid., 177 (X, §4)]. От нашего намерения, разъясняет он, зависит, что и каким образом нужно истолковать, чтобы не нарушить общее правило [Thomasius 1710: $214(\mathrm{X}, \S 4)$ ].

Предложенные схоластиками методы, по мнению Томазия, лишь подтверждают его вывод. Он выделяет у них три метода: синтетический, аналитический и исторический, или метод определения (Historicam, seu Definitivam), который использовал Гален. Основной спор между схоластиками разгорелся по вопросу о том, с каких вещей нужно начинать: с первых для нас (notioribus nobis) или с первых по природе (notioribus natura)? Начинающие с первого по природе, используют синтетический метод, который ведет от принципов к тому, что из них вытекает (a principiis ad principiata), от более простых вещей к сложным [Thomasius 1688: 180 (X, §13)]. Этот метод, по его мнению, всегда ведет к общим понятиям (universalia), с помощью которых схоластики пытаются доказать то, что более известно для нас [ibid., 178 (X, §6)]. Если оценивать этот метод с точки зрения гносеологической субъекта, то он пытается доказать более известное нам с помощью менее известного, что противоречит основному принципу метода. Не лучше обстоят дела, по мнению Томазия, и с аналитическим методом, который используется преимущественно в практической философии. Этот метод исходит из конечной цели и ищет средства для ее достижения. В этике в качестве конечной цели выступает высшее благо, а в качестве средств - добродетели. Однако споры относительно того, является ли благо конечной целью, и являются ли добродетели средствами, ведущими к нему, указывает, по мнению Томазия, на невозможность выработки единых правил метода и здесь [ibid., 182 (X, §16)].

Этими аргументами в основном объясняется отказ Томазия искать особые правила метода и приводить их в систему, как это пытались делать Бартоломей Кеккерман и Клеменс Тимплер. Но и полностью отказаться от правил он не мог. Основная идея Томазия заключалась в создании «легкой» [Haaparanta 2009: 123] и, я бы добавил, естественной логики, которая позволила бы любому человеку легко рассеять заблуждения и избавиться от предрассудков. Томазий фактически предлагает ограничиться двумя правилами: 1) продвигаться от более известного к менее известного, от простого к сложному; 2) связывать удаленные выводы с принципами только посредством ближайших выводов. Эти и некоторые другие правила мы находим у Иоахима Юнга, с логикой которого Томазий был хорошо знаком. Однако Юнг - как впоследствии Эрхард Вайгель и Лейбниц - стремился построить формальную логику, ориентированную на математику, а Томазий - содержательную и практическую.

Характеризовать логику Томазия как психологическую и относить ее к «психологическо-юридическому направлению» в логике [см.: Schenk, 2008] нам представляется не совсем корректным. Томазий не стремится вскрыть психологические основания традиционной логики, а скорее исследует возможности человеческого разума познать истину и его границы. Поэтому его логику правильнее было бы назвать теоретикопознавательной, поскольку ее центральным предметом становится истина. Его учение об истине, как и учение о разуме, базируется на антропологических основаниях. Томазий открыто заявляет, что его учение о разуме касается только человека, т.к. из всех творений только человек обладает разумом [Thomasius 1699: 31 (II, §2)]. И он не скрывает критическую направленность построения логики на антропологических основаниях. Его замысел состоит не только в том, чтобы поставить логику на службу человеку, но прежде всего в том, чтобы исключить из логики все сверхъестественное и, значит, мета- 
физику. «Учение о разуме, - пишет Томазий, - не учит ничему сверхъестественному, а только указывает, как нужно от природы правильно пользоваться разумом, или, скорее, как следует освобождаться от затемнений естественного света» [ibid., 31 (II, §5)].

\section{Гносеологические основания философии и логики Томазия}

В процессе исследования истины Томазий старается следовать «методу математиков», которые требуют начинать с определений и затем их разъяснять. Правда, если математики с помощью определений формулировали аксиомы, Томазий пытается доказать, что в философии, ориентированной на познание истины, принцип должен быть только один. Это вытекает не только из единства цели (познание истины), единства истины, но также из единства разума и присущего ему естественного света. Их единство Томазий рассматривает как самоочевидную истину, ибо представление о наличии у нас двух естественных светов ума он считает абсурдным [Thomasius 1699: 69 (VI, $\S 15)]$. Фактически на этой предпосылке базируется у него исходное определение истины: «То, что согласуется с человеческим разумом, истинно, а то, что противоречит разуму, ложно» [ibid., 70 (VI, §20)]. Это определение он называет primum principorum (первым из принципов). Томазий осознает, что это определение может показаться ложным, поскольку разум содержит чувства и идеи, однако их противопоставление он считает характерным для языческой философии. Своим определением Томазий хотел подчеркнуть, что истина должна согласовываться как с чувствами, так и с идеями. И то, и другое у него относится к мыслям (Gedanken). Только чувства - это «пассивные мысли» (die leidenden Gedanken), а идеи - активные [ibid., 70 (VI, §23)]. Чувства имеют дело с индивидуумами (individuis), а идеи - с универсалиями (universalibus). Исходное определение истины Томазий разъясняет с помощью двух неразрывно связанных между собой определений. Первое гласит: «Что человеческий рассудок познает посредством чувств, то истинно, а что противоречит чувствам, то ложно» [ibid., 71 (VI, §26)]. Согласно второму, «что согласуется с теми идеями, которые человеческий рассудок создает о чувственно воспринимаемых вещах, истинно, а то, что им противоречит, ложно» [ibid., 87 (VI, §100)]. Это не означает, что в основу своего учения он фактически положил два принципа. Для Томазия принципиально важно, чтобы в основе лежал единый принцип, которому были бы подчинены все истины.

Согласно Томазию, именно чувства являются началом всякого познания, тогда как идеи возникают вслед за ними [ibid., 71 (VI, §25)]. За два года до выхода «Опытов» Джона Локка процесс образования идей Томазий представляет следующим образом. Очевидность чувств (sensus evidentia) показывает, что вещи, окружающие дух (mens, Gemüth), конечны и, следовательно, суть индивидуумы. Наш рассудок (Intellectus) их либо смутно представляет (comprehendat) как отдельные (separatim), либо путем сравнения (comparative), направленного на выявления их сходств и различий, отчетливо исследует (speculetur) все их части. Эти умозрения (Speculationes) и представления (Comprehensiones) суть идеи (ideae) и абстракции (abstraciones), поскольку они присущи рассудку, даже если вещи, породившие их, более не присутствуют, и «они таким образом словно бы абстрагированы от вещей, от которых они произошли» (à rebus ortum suum ducebant, sunt quasi abstracta). Поэтому эти умозрения, поскольку они снова связываются с индивидуумами и могут быть указаны, называются конкретными, например, некоторый человек [Thomasius 1688: 134-135 (VII, §3-5)]. Позднее Томазий фактически отождествляет идеи и абстракции [Thomasius 1699: 83 (VI, §80)]. 
Влияние Томаса Гоббса обнаруживается там, где Томазий сравнивает рассуждение с исчислением (computatio) конкретных понятий между собой, утверждение - со сложением (additio) конкретных понятий, а отрицание - вычитанием (substractio) [Thomasius 1688: 135 (VII, §6)]. Однако такая характеристика действий ума для него скорее исключение, чем правило. В своем «Введении в учение о разуме» Томазий говорит о том, что деление и комбинирование должно быть «чистым актом (actus purus) мыслей, который не может возникнуть благодаря простому впечатлению, как страдающие мысли, а... возникает из произвола человека» [Thomasius 1699: 82 (VI, §75)]. ОН подчеркивает, что деление и составление - это единственное, что привносит человеческий рассудок» (das compliment des Menschlichen Verstandes) [ibid., 82 (VI, §76)]. Это самое большее, что может допустить Томазий. Руководствуясь принципом Nihil est in intellectu, quod non prius fuerit in sensu, он утверждает, что активные мысли всегда предполагают (praesupponieren) пассивные [ibid., 83 (VI, §79)].

Таким образом, хотя чувства неразрывно связаны с идеями, именно чувства, согласно Томазию, выступают в качестве исходного критерия истины. Томазий не отрицает, что они могут обманывать. Именно поэтому он требует исследовать их условия, подчеркивая, что знание условий - это плод познания, которое включает в себя также активные мыли [ibid., 72 (VI, §31)]. Обвинения Томазия в «наивном реализме» тоже представляются не совсем корректными. Хотя чувственные образы у него являются результатом воздействия на наш мозг вещей, они все же отличаются от самих вещей, и он в духе эмпиризма утверждает, что виноваты в этом не чувства, а «наши деятельные мысли и суждения» [ibid., 76 (VI, §48)]. Ему чужд сенсуализм и методологический редукционизм, присущий английскому эмпиризму. В духе схоластической традиции, он утверждает, что чувственному познанию доступно только существование, но не сущность. Однако он последовательнее, чем многие из его предшественников, подчеркивает неразрывную связь сущности и существования и, следовательно, чувств и идей. Хотя Томазий, подобно рационалистам, утверждает, что чувства свидетельствую только о существовании вещи, а сущность познает разум, он под сущностью понимает не скрытую за чувственными восприятиями интеллигибельную сущность, а «ее (вещи - C.C.) свойства (Beschaffenheit) или способ (modus), каким вещь воспринимается» [ibid., 43 (IV, §12)]. Под сущностью в строгом смысле он понимает совокупность таких свойств некоторой вещи, благодаря которым мы можем отличить данную вещь от других и без которых мы не можем знать, что она собой представляет [ibid., 44 (VI, §16)]. Сущностей, по его мнению, столько же, сколько вещей. Из принципа единства сущности и существования у него вытекает также то, что «объектом рассуждений являются только вещи, доступные чувственному восприятию» (objectum raticinationis etiam sint res, quae in sensus incurunt) [Thomasius 1688: 134 (VII, §1)]. Может показаться, что Томазий нарушает этот критический принцип эмпиризма, например, когда понимает под материей телесные частицы, из которых состоит субстанция, а под формой - нечто вроде «клея», соединяющего эти частицы в некоторое целое [Thomasius 1699: 51 (IV, §52)]. Однако это не так. В отличие от Декарта, который четко противопоставлял ложь и истину, знание и мнение, Томазий, как и другие эклектики, между истинным и ложным помещает вероятное знание. Подобные утверждения носят гипотетический характер, истинность же гипотез проверяется на опыте. Для эклектиков познание представляет длительный и постепенный процесс приближения к истине. И в этом процессе важную роль играет учение о разуме. Его задача состоит в том, чтобы отграничить истинное от ложного и вероятного. «Учение о разуме» призвано было сформулировать те принципы, в соответ- 
ствии с которыми философ-эклектик должен был отбирать истины, внося свою лепту в формирование коллективной системы достоверного знания, которым могли бы с уверенностью пользоваться будущие поколения ученых. Томазий, как и другие эклектики, признавал только такую систему знаний и решительно отвергал всякого рода априорные спекулятивные системы. Свою логику он также рассматривал как результат критического отбора всего того, что было истинным у его предшественников. Это дало основание некоторым историкам философии относит его к основоположникам систематического эклектицизма. Так, оценивая заслуги Томазия, Густав Царт утверждал: «Основоположником систематического эклектицизма считается Томазий, который в своей логике отобрал лучшее из того, что он нашел в других новых учебниках по логике, и подчеркнул пользу, какую несет с собой знание различных взглядов на природу вещей и человека, т.к. оно ведет к познанию чужих заблуждений и дает возможность исследовать истину, о которой мы иначе бы не думали» [Zart 1881: 34].

\section{Bblводbl}

Реформа логики, предпринятая Томазием, была частью той реформы философии, которую он задумал. Суть ее состояла в очищении философии от всех предрассудков и придание ей возможности по-настоящему служить человеку. Этой задачей определяется и соответствующая структура философского учения: изложению философии предшествует критическое историко-философское введение, а последнему - учение о разуме, которое, по замыслу Томазия, призвано было заменить традиционную метафизику. Основную задачу учения о разуме Томазий видит в прояснении понятия истины и тех принципов, на основании которых следует осуществлять критическую оценку суждений своих предшественников и современников. В логике острие его критики было направлено против формализма и методизма традиционной логики, а в метафизике - против всякого рода спекуляций. Свою логику Томазий сознательно строил на принципах философской антропологии. Критический смысл такой логики состоял в том, чтобы ограничить сферу поиска истины тем, что доступно человеческому разуму, исключив из нее всякого рода метафизические спекуляции. Она была логикой содержательной, носила диалогический и критический характер, и предназначалась не для построения метафизических систем, а для критического анализа суждений оппонентов. Однако ее функции не ограничивались критикой. Свою логику, как логику открытия, Томазий противопоставляет силлогистике. Ее можно рассматривать как один из ранних вариантов построения гносеологической логики, близкой по духу современным неформальным логикам и теориям аргументации.

\section{СПИСОК ЛИТЕРАТУРЫ / REFERENCES}

Haaparanta, L. (2009). Development of Logic. Oxford: Oxford UP. https://doi.org/10.1093/acprof:oso/9780195137316.001.0001

Lehmann-Brauns, S. (2004). Weisheit in der Weltgeschichte. Philosophiegeschichte zwischen Barock und Aufklärung. Tübingen: Niemeyer.

Menzel, W. W. (1996). Vernakuläre Wissenschaft: Christian Wolffs Bedeutung für die Herausbildung und Durchsetzung des Deutschen als Wissenschaftssprache. Tübingen: Niemeyer. https://doi.org/10.1515/9783110941036

Petersen, P. (1921). Geschichte der Aristotelischen Philosophie im Protestantischen Deutschland. Leipzig: Meiner. 
Schenk, G., \& Meier, R. (Eds.). (2008). Psychologisch-Juristische Richtung der Logik im 18. Jahrhundert in Halle: Thomasius, Buddeus, Sperlette, Schneider, Grundling, Heineceius. Halle: Schenk.

Schmidt-Biggemann, W. (1988). Zwischen dem Möglichen und dem Tatsächlichen. Rationalismus und Eklektizismus, die Hauptrichtungen der deutschen Aufklärungsphilosophie. In W. Schmidt-Biggemann, Theodizee und Tatsachen. Das philosophische Prophil der deutschen Aufklärung (SS. 7-57). Frankfurt am Main.

Schneiders, W. (1993). Vorwort. In Ch. Thomasius, Ausgewälte Werke. Bd. 1: Introduction ad philosophiam aulicam. Hildesheim, Zürich, \& New York: Olms.

Scholz, L. (2002). Das Archiv der Klugheit: Strategien des Wissens um 1700. Tübingen: Niemeyer. https://doi.org/10.1515/9783110953497

Thomasius, Ch. (1688). Introductio ad philosophiam aulicam, seu lineae primae libri de prudentia cogitabdi et ratiocinandi. Lipsiae: Apud Autorem.

Thomasius, Ch. (1699). Einleitung zu der Vernunft-Lehre. Halle: Christoph.

Thomasius, Ch. (1710). Einleitung zu Hof-Philosophie. Frankfurt, \& Leipzig: Bauer.

Thomasius, Ch. (1713). Höchstnöthige Cautelen. Halle im Magdeburg: Renger.

Thomasius, Ch. (1773). Dissertationum academicarum varii inprimis iuridici argumenti. Halae Magdeburgae: Gebaueri et Filii.

Zart, G. (1881). Einfluß der englischen Philosophie seit Bacon auf die deutsche Philosophie des 18. Jahrhunderts. Berlin: Dümmler.

Одержано / Received 22.07.2017

\section{Sergiy Secundant}

\section{Christian Thomasius: logic as the doctrine of reason}

In this article the Thomasius's logic is estimated not from the point of view of formation of modern formal logic, but as one of the first attempts to create a non formal logic or a theory of the argument. His reform of logic was a part of his reform of the philosophy directed to release of the person from prejudices and to emergence of a new creative person. The author considers that Christian Thomasius's logic cannot be regarded as a psychological or a juridical logic. It is rather an epistemological one that is focused mainly on a philosophical discourse. The purpose of such logic consists in delimiting true from false, probable from improbable. It is based on the anthropological bases. His anthropology is constructed on the epistemological principles of empiricism and performs critical functions: it is directed against a formalism and methodism of traditional logic. Understood as the doctrine about human reason, Thomasius's logic is called to serve as a tool of the criticism in a substantive rational discourse, including philosophical, and it, as such, becomes basis of all his philosophy.

Sergiy Secundant, Doctor of sciences in philosophy, associated professor of Department of Philosophy and Grounds of Humanities at I. Mechnikov Odessa National University.

Сергій Секундант, д. філос. н., доцент кафедри філософії та основ загальногуманітарного знання Одеського начіонального університету ім. I. Мечнікова.

Сергей Секундант, д. филос. н., дочент кафедры философии и основ общегуманитарного знания Одесского начионального университета им. И. Мечникова.

e-mail: sergiisekundant@gmail.com 